\title{
Analytic derivation of central axis percent depth dose calculations in transition zones with loss of electronic equilibrium
}

\author{
John M Pacyniak \\ Fort Belvoir Community Hospital, Fort Belvoir, Virginia, USA
}

Received November 18, 2015; Revised July 05, 2016; Accepted July 07, 2016; Published Online July 16, 2016

Original Article

\begin{abstract}
Purpose: The study of megavoltage photon dose distribution behind and near small areas of low and high density material is best understood with Monte Carlo (MC) dose calculation or direct measurements which may not be always be possible. This is especially true for air-tissue area where the replacement of soft tissue scattering material by air results in the loss of electronic equilibrium and changes in the lateral spread of the beam as well. Monte Carlo calculations are the standards to correctly evaluate in homogeneities in transition zones. If one could develop a model with sufficient accuracy to obtain similar results, this would be very helpful clinically. Methods: To this end, we have developed an exponential model and derive an explicit expression that accounts for the under dosage. The model is an extension of a much earlier work done with electrons and photons. Our analytic model is based on the experience of the underlying physics assuming exponential attenuation of photons in matter. Results: It differs from a similar work by solving the problem correctly and introducing parameters that can be traced to direct measurements without the need of extensive statistical data analysis. It combines the generation of free electrons through ionization and their attenuation to a simple differential equation for the central axis depth dose. It involves two parameters, which can be obtained from 1) direct beam measurements, 2) primary photon attenuation coefficients from physics tables and 3) iteration techniques. Conclusion: The simplicity of the model allows us to extend our derivation to situations such as transitions zones of different densities in areas such as head and neck and lung. A clinical example is illustrated to demonstrate the problems encountered in treating cancer of the larynx.
\end{abstract}

Keywords: Monte Carlo, Electronic Disequilibrium, Heterogeneity

\section{Introduction}

High energy photons ionize matter indirectly; photon interactions in a medium release charged particles (electrons or positrons), which in turn deposit energy via Coulomb interactions with orbital electrons of the atoms. The intensity of a monoenergetic photon beam, $\mathrm{I}_{\mathrm{p}}$, incident on a medium attenuates according to the exponential law:

$I_{p}(x)=I_{o} e^{-\mu(E) x}$,

Io is the initial photon intensity, E the energy of the photon, $\mu$ linear attenuation coefficient for the medium and $x$ is the depth of interest. Eq. (1) represents the primary component of the photon beam. The linear attenuation coefficient $\mu$ is the sum of the attenuation coefficients of several interactions,

$\mu=\tau+\sigma_{R}+\sigma_{C}+\kappa$

where $\tau$ denotes the photo-electric coefficient effect, $\sigma_{R}$ for Rayleigh scattering, $\sigma_{\mathrm{C}}$ for Compton scattering and $\kappa$ for pair productions. The most important interaction in the therapeutic range is Compton scattering, which dominates in the energy range of 6 to 18 MV X-rays.

Corresponding author: John M Pacyniak; Fort Belvoir Community Hospital, Fort Belvoir, Virginia, USA. Email: jpacyniak@msn.com 


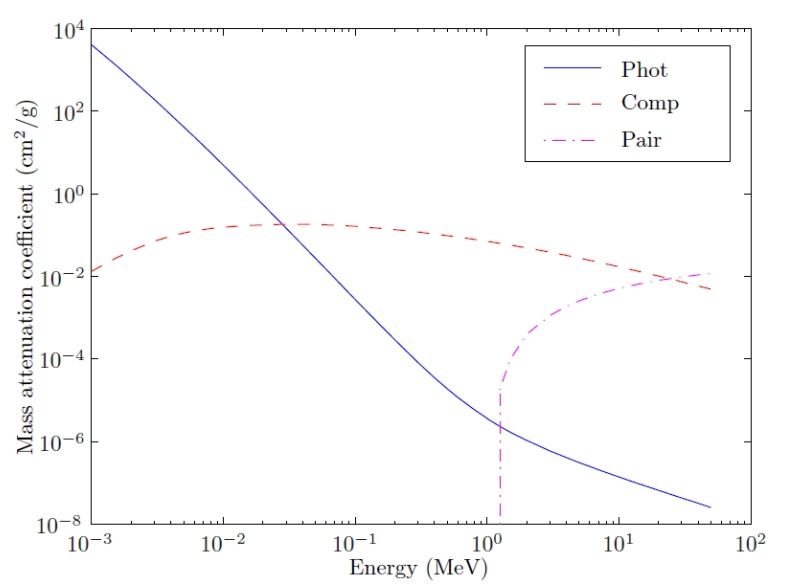

Figure 1: Mass attenuation coefficients for water for three major photon interactions.

The absorbed dose is defined as the mean energy $\mathrm{E}$ deposited by ionizing radiation to a medium of mass $\mathrm{m}$ in a finite volume V. For monoenergetic photons traveling along a depth $\mathrm{x}$, the absorbed dose can be written as

$\left.\mathrm{D}(\mathrm{x})_{\text {med }}=(1 / \rho)(\mathrm{dE} / \mathrm{dx})\right)_{\mathrm{med}, \mathrm{Av} .} \Phi(\mathrm{x})$

where $(1 / \rho)(\mathrm{dE} / \mathrm{dx})$ med, Av., also known as the Stopping Power $(\mathrm{S} / \rho)_{\text {med, } A v}$, is the average energy loss along the depth $\mathrm{x}$ and $\Phi(\mathrm{x})$ is the fluence or number of secondary electrons, $\mathrm{I}_{\mathrm{e}}(\mathrm{x})$, generated by the incident photons. Taking into account the fact that the photon fluence is inversely proportional to the square of the distance from the source, Equ.(3) becomes

$\mathrm{D}(\mathrm{x})_{\text {med }}=(\mathrm{S} / \rho)_{\text {med, } A v} \mathrm{Ie}_{\mathrm{e}}(\mathrm{x}) \quad[\mathrm{f} /(\mathrm{f}+\mathrm{x})]^{2}$

The central axis depth dose is defined as the ratio of the central axis dose divided by the maximum dose on the central axis, that is;

$\% \mathrm{D}(\mathrm{x})=100\left[\mathrm{D}(\mathrm{x}) / \mathrm{D}\left(\mathrm{x}_{\max }\right)\right]$

The purpose of this paper is to show that by means of a simple analysis of first order scattering of high energy photons in a an absorbing medium it is possible to compute, for practical purposes, the distribution of secondary radiation in an absorber containing a region of a different density and derive the way the total radiation is attenuated. Our solution can account for the radial distribution of the beam by multiplying the central axis by a simple empirical factor $\mathrm{F}(\mathrm{x}, \mathrm{y})$ which takes into account the non-planarity of the field as well as the sidewise straggling and scattering of electrons. This will be the subject of a future investigation.

In Appendix A, we proceed to derive the central axis depth dose for a homogeneous case. In Appendix B, we derive the solutions for inhomogeneous case, present the necessary boundary conditions, and discuss the meanings of the parameters $\mu_{\rho}, \mu_{e}$, and explain their variations with energy loss due to different densities. Lastly, we present a comparison of calculated depth doses for a Varian 21iX Clinac and check the validity of our model with a Monte Carlo simulation of interface regions near closed air cavities. A clinical example is illustrated to demonstrate the problems encountered in treating cancer of the larynx and suggestions for improving the situation are cited.

\section{Methods and Materials}

\subsection{Theory}

High-energy photons incident on a homogeneous material of density $\rho$ are gradually attenuated. Each centimeter of material attenuates a constant fraction of the initial intensity. As a consequence, their intensity follows an exponential decay law.

$I_{p}(x)=I_{o} \exp \left(-\mu_{p} x\right)$

where, $\operatorname{Ip}_{p}(x)$ is the intensity left a depth $x, I_{0}$ is the incident intensity and $\mu_{\rho}$ an effective linear attenuation coefficient for the photons in the given material. $\mu_{\mathrm{p}}$ $\left(\mathrm{cm}^{-1}\right)$ depends on the photon energy, type of medium and its value decreases with higher energies. Values for $\mu_{p}$ can be found in physics reference data tables or calculated from measured beam data. The primary effect of photons is to knock out electrons from the cell material. The energy lost by the photons is converted into ionization energy. These ionization electrons or electron fluence are proportional to absorbed dose from which the central axis \% percentage depth dose is derived. This is an extension of our earlier work. ${ }^{1,2}$ The derivation is given in Appendix A and the solution is

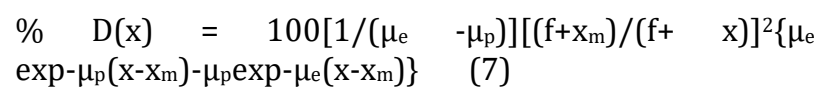

At $x=0$,

$\left.\% \mathrm{D}(0)=100\left[1 /\left(\mu_{\mathrm{e}}-\mu_{\mathrm{p}}\right)\right]\left[\left(\mathrm{f}+\mathrm{X}_{\mathrm{m}}\right) / \mathrm{f}\right)^{2}\right]\left[\mu_{\mathrm{e}} \exp \left(\mu_{\mathrm{p}} \mathrm{X}_{\mathrm{m}}\right)-\mu_{\mathrm{p}}\right.$ $\left.\exp \left(\mu_{\mathrm{e}} \mathrm{X}_{\mathrm{m}}\right)\right]$

(8)

The surface dose is small but not zero. It is interesting to note that Eq. (7) agrees closely with the form obtained empirically by Johns et $a l^{5}$ many years ago and others (Tahmasei et al.) ${ }^{3,6}$. The difference lies in the fact that we have derived Eq. (7) from a model, which has allowed us to state precisely the assumptions given, the necessary approximations and the meaning of the different coefficients. Eq. (7) calculates the central axis $\%$ percentage depth dose for high energy photons as a function of the average photon energy, $\mu_{\mathrm{p}}$, an average secondary electron factor, $\mu_{\mathrm{e}}$, source to skin distance $\mathrm{f}$ and depth of maximum dose $\mathrm{x}_{\mathrm{m}}$. Figures 2 \& 3 illustrate the calculated vs. measured $\%$ depth dose for field sizes 
$2 \times 2$ to $40 \times 40 \mathrm{~cm}^{2}$ with an accuracy of $\pm 2 \%$ over a range of 0 to $30 \mathrm{~cm}$ depth. In Figure 4, we compared the calculated \% central axis depth dose Eq. (7) against the
Eclipse AAA for a $10 \times 10 \mathrm{~cm}^{2}$ and found excellent agreement.

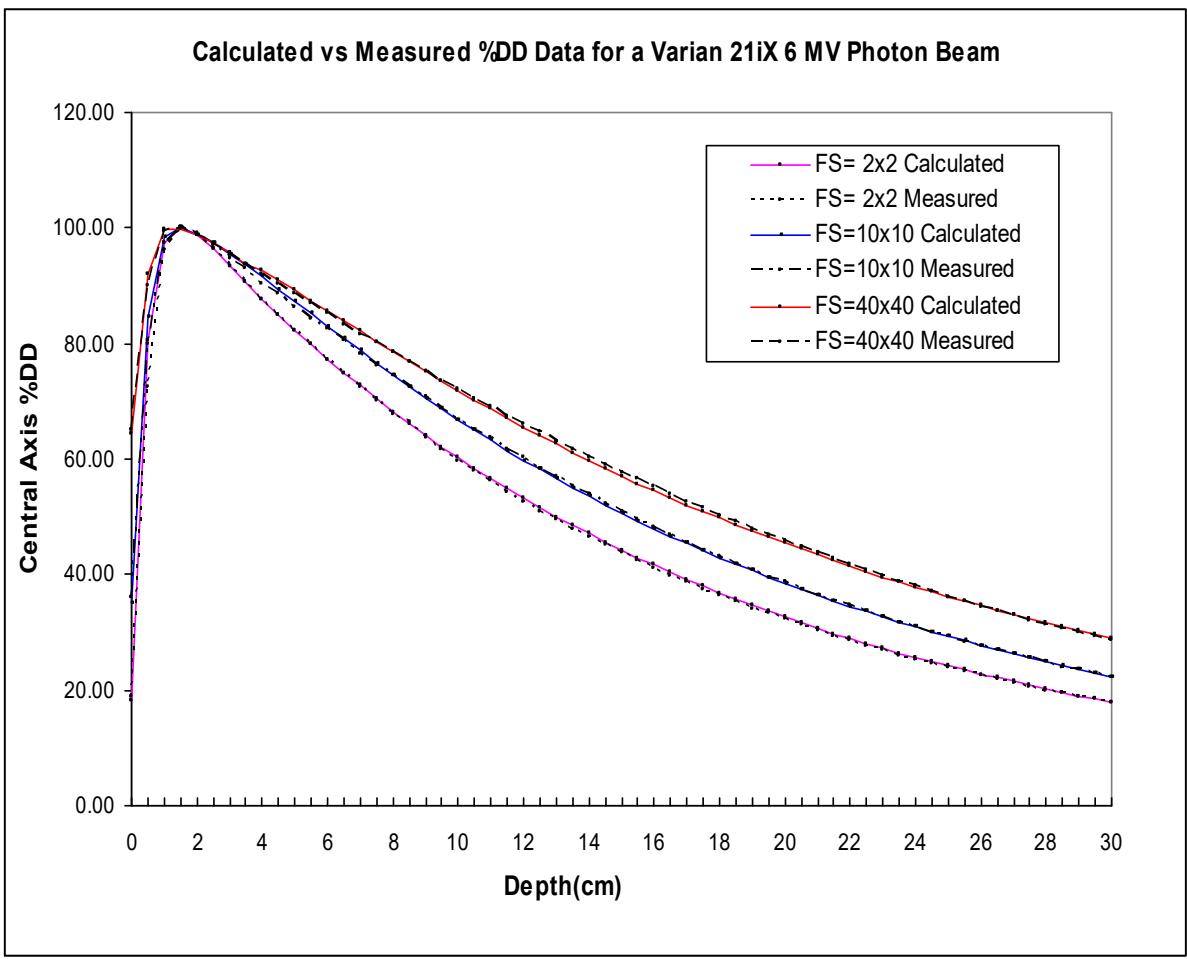

Figure 2: Calculated vs. measured \%DD for a Varian 21iX Clinac 6 MV photons.

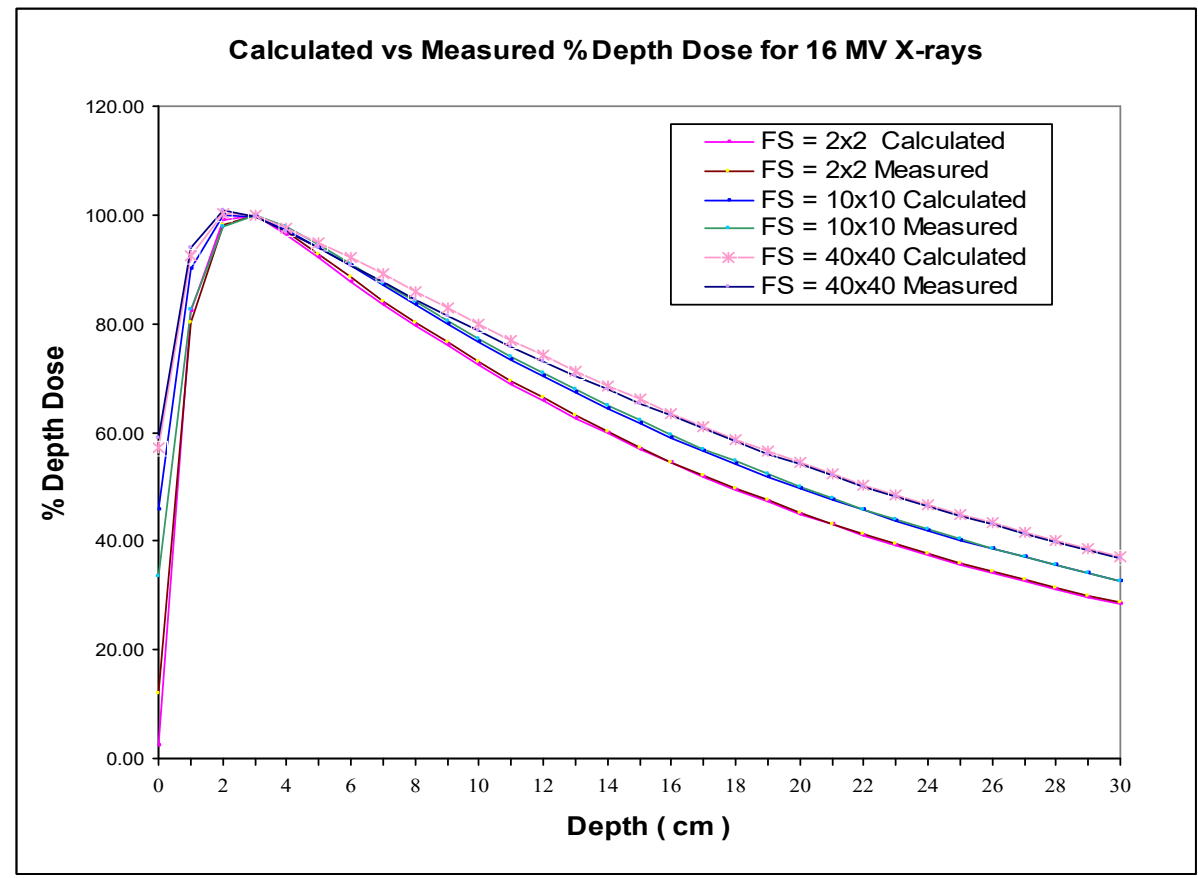

Figure 3: Calculated vs. measured \%DD for a Varian 21iX 16 MV photons. 


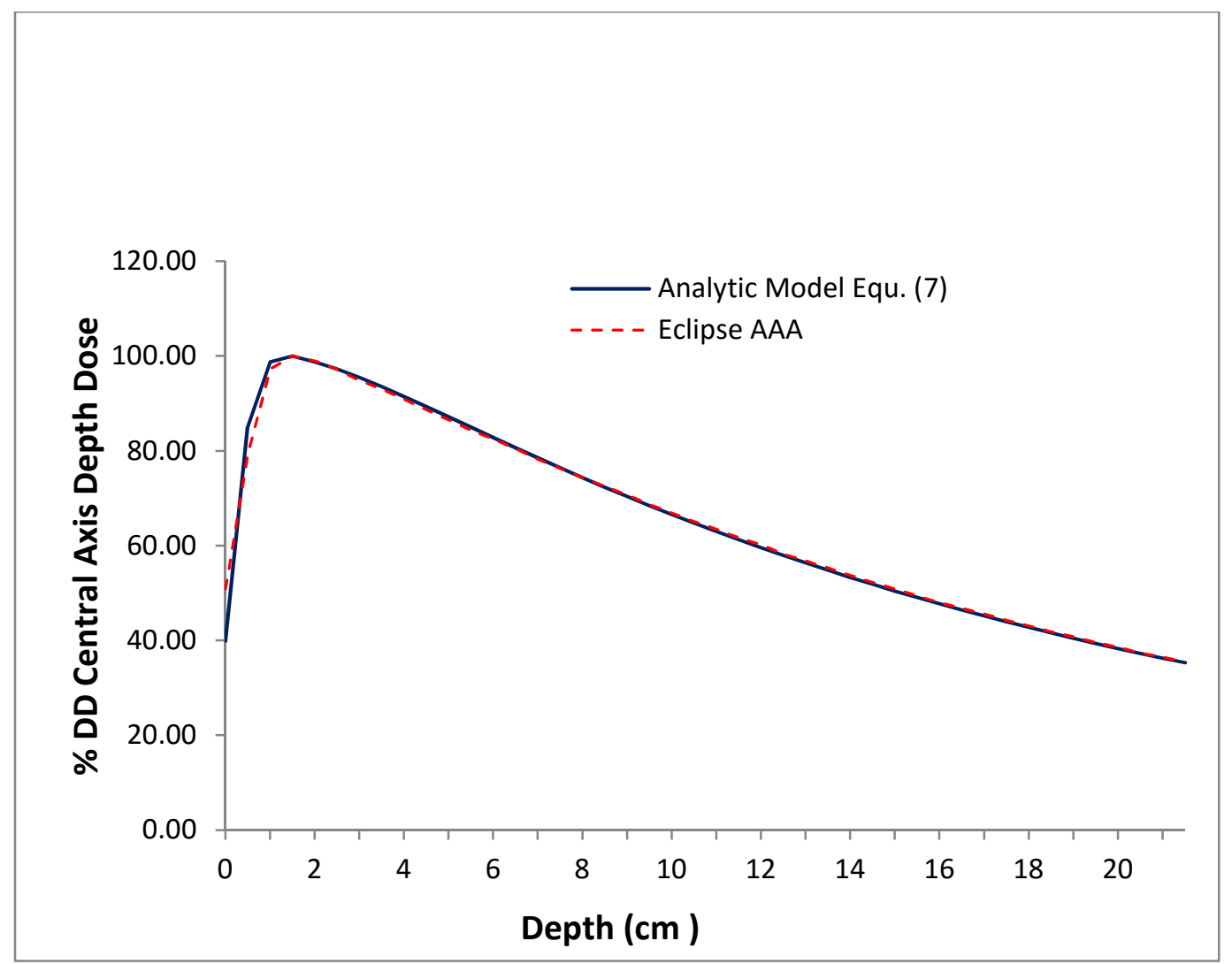

Figure 4: Central axis \% depth dose calculations based on equation (7) vs. Varian AAA algorithm.

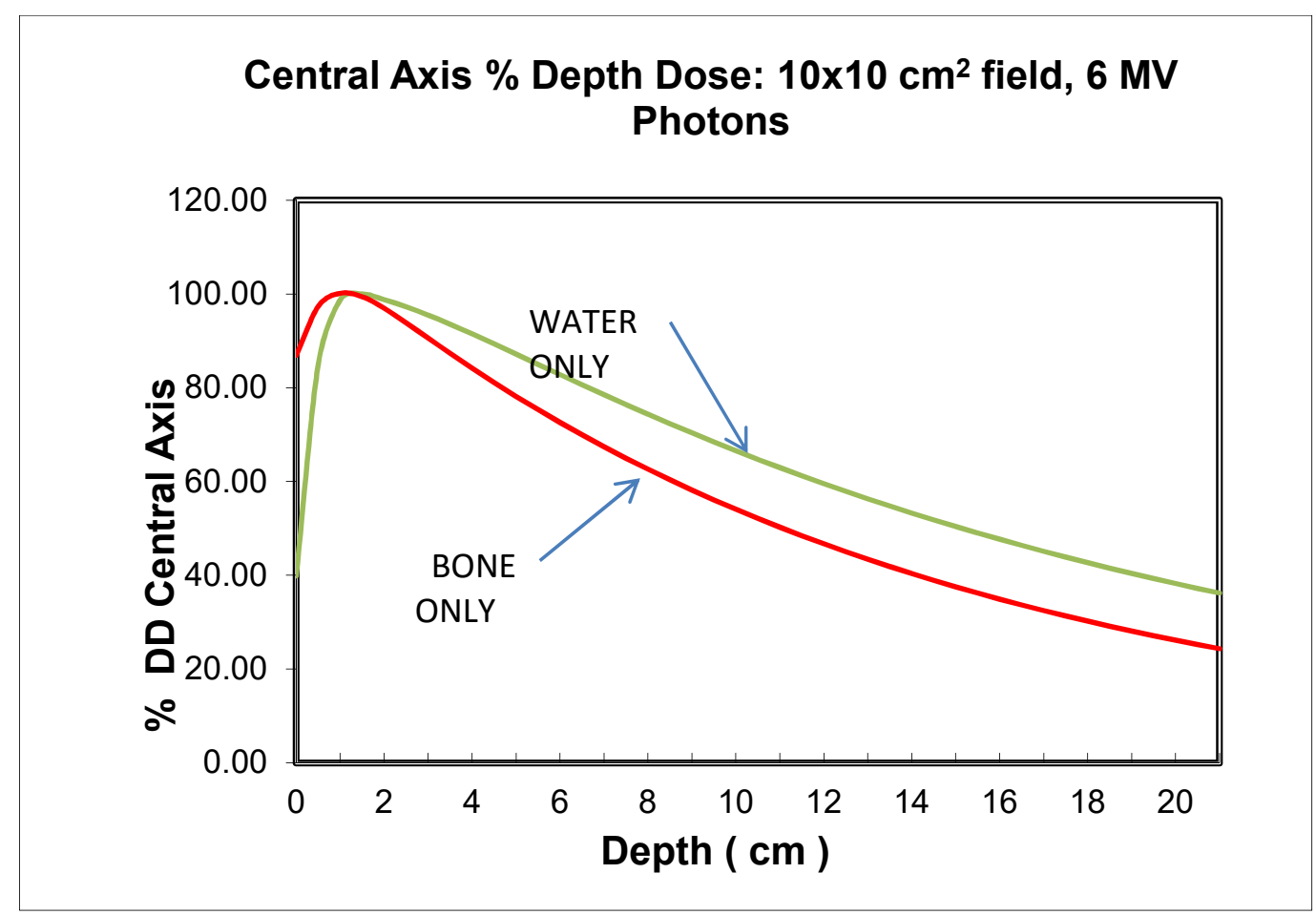

Figure 5: The \% central axis depth dose calculated for water and bone respectively. 
Table 1: Calculated $\mu_{\mathrm{p}}$ from a Varian 21iX $6 \mathrm{MV}$ photon measured data.

\begin{tabular}{cccc}
\hline \hline $\mathrm{Ip}(\mathrm{X} 1)$ & $\mathrm{I}_{\mathrm{p}}(\mathrm{x} 2)$ & $\mathrm{FS} \mathrm{cm}{ }^{2}$ & $\mu_{\mathrm{p}}\left(\mathrm{cm}^{-1}\right)$ \\
\hline 0.600 & 0.178 & $2 \times 2$ & 0.045 \\
0.623 & 0.190 & $4 \times 4$ & 0.043 \\
0.639 & 0.202 & $6 \times 6$ & 0.041 \\
0.669 & 0.223 & $10 \times 10$ & 0.038 \\
0.698 & 0.256 & $20 \times 20$ & 0.033 \\
0.720 & 0.285 & $40 \times 40$ & 0.029 \\
\hline \hline
\end{tabular}

After calculating $\mu_{\mathrm{p}}$ for the appropriate field size, we refer to Reference Table 4and locate the effective energy corresponding to the value of $\left(\mu_{\mathrm{p}} / \rho\right)$ which in our case is 3.20 MV. With this energy value, we can search for the primary linear attenuation coefficient for bone. Using an average density of $1.5 \mathrm{gm} / \mathrm{cm}^{3}$

$\mu_{\mathrm{p}}($ bone $) / \rho=0.0373 \mathrm{~cm}^{2} / \mathrm{gm} \times 1.50 \mathrm{gm} \mathrm{cm}^{-3}=0.055$ $\mathrm{cm}^{-1}$

Our next step is to calculate the central axis \% depth dose in a medium made up of bone only.

These following data was used to generate the central axis \% depth dose in bone only.

$\mathrm{X}_{\mathrm{m}}=1.3 \mathrm{~cm} \quad \mu_{\mathrm{e}}=1.9 \mathrm{~cm}^{-1}$

Due to lack of measured data, we approximated values for $\mathrm{x}_{\mathrm{m}}$, and $\mu_{\mathrm{e}}$. Computer Monte Carlo simulation ${ }^{8}$ of a 6 MV photon beam in heterogeneous media containing bone, demonstrate that the absorbed dose is $11.1 \%$ lower in bone than in water for the same depth. Figure 5 shows the \% central axis depth dose calculated for water and bone respectively.

\subsection{Secondary Attenuation Coefficient $\left(\mu_{\mathrm{e}}\right)$}

The electron absorption coefficient depends not only on field size but on depth as well. The effects of electronic equilibrium require that two separate values be used for $\mu_{\mathrm{e}}$. For $\mathrm{x}<\mathrm{xm}$, in the buildup region, secondary electrons will be attenuated 1 more quickly than beyond the buildup region and will have a larger numerical value. The parameter $\mu_{\mathrm{e}}$ for $\mathrm{x}<\mathrm{x}_{\mathrm{m}}$ and $\mathrm{x}>\mathrm{x}_{\mathrm{m}}$ cannot be solved analytically but using an iteration technique, an approximate value can be obtained for a given depth and field size. The following method is used to determine the best values for $\mu_{\mathrm{e}}$

\section{Example 1: $\mathrm{x}<\mathrm{x}_{\mathrm{m}}$}

Given: FS $=10 \times 10 ;$ depth $=1.0 \mathrm{~cm} ; \mu_{\mathrm{p}}=0.038 \mathrm{~cm}^{-1}$; Measured \%DD $(1,100)=97.4$

We start with an arbitrary value of $\mu_{\mathrm{e}}=2.60 \mathrm{~cm}^{-1}$
Inserting the value of $2.60 \mathrm{~cm}^{1}$, we calculate $\% \mathrm{D}(\mathrm{x}, \mathrm{f})$ with $\operatorname{Eq}(7)$

$\% \mathrm{DD}(1,100)=98.96$ which is close to the measured value of 97.4. Since the agreement is within $2 \%$, we accept the value of $\mu_{\mathrm{e}}=2.60 \mathrm{~cm}^{-1}$ and proceed to calculate the central axis depth dose for $\mathrm{x}<\mathrm{x}_{\mathrm{m}}$.

\section{Example 2: $\mathrm{x}>\mathrm{x}_{\mathrm{m}}$}

From Eq. (7),

$\% D(x, f)=100\left(1 /\left(\mu_{e}-\mu_{p}\right)\right)\left(\left(f+x_{m}\right) /(f+x)\right)^{2}\left\{\mu_{e} e^{-\mu} p^{\left(x-x_{m}\right.}\right)-\mu$ $\left.\mathrm{e}^{-\mu_{\mathrm{e}}\left(\mathrm{x}-\mathrm{x}_{\mathrm{m}}\right)}\right\}$

let $\Delta=\left(\mathrm{x}-\mathrm{xm}_{\mathrm{m}}\right)$ and $\mathrm{D}=((\mathrm{f}+\mathrm{xm}) /(\mathrm{f}+\mathrm{x}))^{2}(\% \mathrm{D}(\mathrm{x}, \mathrm{f}) / 100)$

$\mathrm{D}=\left(1 /\left(\mu_{\mathrm{e}}-\mu_{\mathrm{p}}\right)\right)\left(\mu_{\mathrm{e}} \mathrm{e}^{-\mu_{\mathrm{p}}} \Delta-\mu_{\mathrm{p}} \mathrm{e}^{-\mu_{\mathrm{e}}} \Delta\right)$

$\left(\mu_{\mathrm{e}}-\mu_{\mathrm{p}}\right) \mathrm{D}=\mu_{\mathrm{e} 1} \mathrm{e}^{-\mu_{\mathrm{p} 1} \Delta}-\mu_{\mathrm{p} 1} \mathrm{e}^{-\mu_{\mathrm{e} 1} \Delta}$

$\mu_{\mathrm{e} 1}\left(\mathrm{D}-\mathrm{e}^{-\mu_{\mathrm{p}} \Delta} \Delta\right)=\mu_{\mathrm{p}}\left(\mathrm{D}-\mathrm{e}^{-\mu_{\mathrm{e}}} \Delta\right)$

$\mu_{\mathrm{e}}=\mu_{\mathrm{p}}\left(\mathrm{D}-\mathrm{e}^{-\mu_{\mathrm{e}}} \Delta\right) /\left(\mathrm{D}-\mathrm{e}^{-\mu_{\mathrm{p}}} \Delta\right)$

For a given $\mathrm{x}, \mu_{\mathrm{e}}$ is solved as follow:

for $\mathrm{j}=0.1$ to 10

$\mu_{\mathrm{e}}(\mathrm{j})=\mu_{\mathrm{p}}\left(\mathrm{D}-\mathrm{e}^{-\mathrm{j}} \Delta\right) /\left(\mathrm{D}-\mathrm{e}^{-\mu_{\mathrm{p}}} \Delta\right)$

When $\mu_{e}(j)=\mu_{e}(j+1)$, then $\mu_{e}(j)=\mu_{e}$

When the iteration stops we record the value for $\mu_{\mathrm{e}}$ as 0.53 .

We have assumed that the average secondary electron energy of $\mathrm{Ie}(\mathrm{x})$ is proportional to the average photon energy and will vary with field size and depth. The effects of electronic equilibrium require two separate values for $\mu_{\mathrm{e}}$, that is, for $\mathrm{x}<\mathrm{x}_{\mathrm{m}}$ and $\mathrm{x}>\mathrm{x}_{\mathrm{m}}$. (See Table 2)

Table 2: Secondary linear absorption coefficient $\mu_{\mathrm{e}}$ as a function of FS and depth $\left(\mathrm{x}<\mathrm{x}_{\mathrm{m}}\right.$ and $\left.\mathrm{x}>\mathrm{x}_{\mathrm{m}}\right)$.

\begin{tabular}{ccc}
\hline \hline Field Size & $\mu_{\mathrm{e}}\left(\mathrm{x}<\mathrm{x}_{\mathrm{m}}\right) \mathrm{cm}^{-1}$ & $\mu_{\mathrm{e}}\left(\mathrm{x}>\mathrm{x}_{\mathrm{m}}\right) \mathrm{cm}^{-1}$ \\
\hline $2 \times 2$ & 2.32 & 1.50 \\
$4 \times 4$ & 2.45 & 1.00 \\
$6 \times 6$ & 2.65 & 0.72 \\
$10 \times 10$ & 2.80 & 0.50 \\
$20 \times 20$ & 3.00 & 0.40 \\
$40 \times 40$ & 3.30 & 0.30 \\
\hline \hline
\end{tabular}




\subsection{Central axis percent depth dose derivation for inhomogeneous case}

The introduction of a region with density other than the medium causes a reduction or increase of the dose along the central axis. It will be shown that the dose at $\mathrm{x}=\mathrm{a}$ will be reduce by a factor proportional to the ratio of the stopping power of air to that of tissue. At $x=b$, the depth dose distribution will be more complicated. However, the problem is simplified by solving the dose in each specific region.

\subsubsection{Boundary Conditions}

Region 1: $0 \leq \mathrm{x} \leq \mathrm{a}$

$$
I_{p 1}(x)=I_{0} e^{-\mu} 1^{x}
$$

Region 2: $\mathrm{a} \leq \mathrm{x} \leq \mathrm{b}$

$$
\mathrm{I}_{\mathrm{p} 2}(\mathrm{~b}-\mathrm{x})=\mathrm{I}_{0} \mathrm{e}^{-\mu_{\mathrm{p} 1}} \mathrm{a}^{\mathrm{a}} \mathrm{e}_{\mathrm{p} 2}(\mathrm{~b}-\mathrm{x})
$$$$
\mathrm{I}_{\mathrm{e}}(\mathrm{a})=\mathrm{I}_{\mathrm{e}}(\mathrm{a})
$$

Region 2: $\mathrm{x} \geq \mathrm{b}$

$$
\begin{aligned}
& I_{p 3}(x-b)=I_{0} e^{-\mu_{p 1}}{ }^{a} e^{-\mu_{p 2}} e^{-\mu_{p 3}}(x-b) \\
& I_{e 2}(b)=I_{e 3}(b)
\end{aligned}
$$

$\% \mathrm{DD}_{1}(\mathrm{a}) \neq \% \mathrm{DD}_{2}(\mathrm{a})$

$\% \mathrm{DD}_{2}(\mathrm{~b}) \neq \% \mathrm{DD}_{2}(\mathrm{~b})$

$\mathrm{X}_{\mathrm{m} 1} \neq \mathrm{Xm}_{2} \neq \mathrm{X} \mathrm{m} 3$

\subsection{Central axis \% Depth Dose Equations for each Region}

Region I: $0 \leq \mathrm{x} \leq \mathrm{a}$

$\% \mathrm{D}(\mathrm{x})=100\left[1 /\left(\mu_{\mathrm{e}}-\mu_{\mathrm{p}} \quad\right)\right] \quad\left[\left(\mathrm{f}+\mathrm{x}_{\mathrm{m}}\right) /(\mathrm{f}+\quad \mathrm{x})\right]^{2}\left\{\mu_{\mathrm{e}}\right.$ $\left.\exp -\mu_{\mathrm{p}}\left(\mathrm{x}-\mathrm{x}_{\mathrm{m}}\right)-\mu_{\mathrm{p}} \exp -\mu_{\mathrm{e}}\left(\mathrm{x}-\mathrm{x}_{\mathrm{m}}\right)\right\}$

Region II: $\mathrm{a} \leq \mathrm{x} \leq \mathrm{b}$

$\% \mathrm{D}_{2}(\mathrm{x}-\mathrm{a})=100\left(\mathrm{~S}_{2} / \mathrm{S}_{1}\right)\left[(\mathrm{f}+\mathrm{a})\left(\mathrm{f}+\mathrm{x}_{\mathrm{m} 1}\right) /(\mathrm{f}(\mathrm{f}+\mathrm{a}+\mathrm{x})]^{2}\right.$

$\times\left\{\mu_{\mathrm{e} 1} \exp -\mu_{\mathrm{p} 1}\left(\mathrm{a}-\mathrm{x}_{\mathrm{m} 1}\right)-\mu_{\mathrm{p} 1} \exp -\mu_{\mathrm{e} 1}\left(\mathrm{a}-\mathrm{x}_{\mathrm{m} 1}\right)\right\} \mathrm{e}^{-\mu_{\mathrm{e} 2}}{ }^{(\mathrm{x}-\mathrm{a})}$

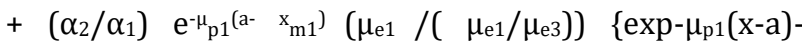
$\left.\exp -\mu_{\mathrm{e} 1}(\mathrm{x}-\mathrm{a})\right\}$

$S_{2}$ and $S_{1}$ are the stopping power for medium 2 and 1.
Region III: $\mathrm{x} \geq \mathrm{b}$

$\% \mathrm{D}_{3}(\mathrm{x}-\mathrm{b})=100\left(\mathrm{~S}_{3} / \mathrm{S}_{1}\right)\left(\alpha_{3} / \alpha_{1}\right)\left(\mu_{\mathrm{e} 3} / \mu_{\mathrm{e} 1}\right)\left[1 /\left(\mu_{\mathrm{e} 3}-\mu_{\mathrm{p} 3}\right)\right]$ $(\mathrm{f}+\mathrm{b}) /(\mathrm{f}+\mathrm{b}+\mathrm{x})(\mathrm{f}+\mathrm{xm} 1) / \mathrm{f})^{2}$

$\times\left(\mathrm{e}^{-\mu_{\mathrm{p} 1}} \mathrm{e}^{\mathrm{a}} \mathrm{\mu}_{\mathrm{p}}{ }^{(\mathrm{b}-\mathrm{a})} \mathrm{e}^{-\mu_{\mathrm{p} 3}{ }^{\mathrm{a}} \mathrm{xm} 3}\right)$

$\times\{\mu \mathrm{e} 3$ exp- $\mu \mathrm{p} 3(\mathrm{x}-\mathrm{b}-\mathrm{xm} 3)-\mu \mathrm{p} 3$ exp- $\mu \mathrm{e} 3(\mathrm{x}-\mathrm{b}-\mathrm{xm} 3)\}$ (11)

$S_{3}$ and $S_{1}$ are the stopping power for medium 3 and 1.

The effective/average energy for the \% depth dose in water, is obtained from photon interaction coefficients tables. ${ }^{4}$ This also allowed us to extrapolate the average photon energies and stopping power ratio for different medium. The dependent parameters as a function of field size, $\mu_{\mathrm{e}}, \mu_{\mathrm{p}}, \alpha, \mathrm{x}_{\mathrm{m}}$ and $\mathrm{S}$ were calculated and obtained from measured data. (See Table 3) Figure 6 shows the central axis \% depth dose for 6 and 16 MV photons with and without an air gap.

The results agree with findings from Monte Carlo studies.7,8,9,10,11 For higher energies, the changes will be more pronounced. Based on our model, the calculations show that small fields have a greater reduction at the air junction (interface) zone than larger field sizes. Higher energies also exhibit higher dose reductions near air-tissue interface zone.

The primary photon linear attenuation coefficient in low density areas such air cavities is much less than values of tissue equivalent materials such as water and therefore cause a decrease in the dose distribution due to reduced generation of scattered electrons as reflected by the coefficient $\alpha$ in Eq.(31). This causes electronic disequilibrium and loss of dose in the region. Beyond the air cavity, there is an increase of dose. The primary reason for this is the increase in the production of electrons and reflected by the coefficient $\alpha$.

For densities > $1 \mathrm{gm} / \mathrm{cm}^{3}$ such as bone, the electron density and the linear attenuation is higher than water but the mass attenuation per gram of bone is less than water and causes a decrease of dose. At the interface of bone and soft tissue, there is an increase of dose due to backscatter of electrons from the bone surface and a buildup region of a few millimeters occurs. (Figure 7)

Table 3: Parameters used in central axis \% depth dose calculations.

\begin{tabular}{cccccc}
\hline \hline FS & FS $\mu_{\mathrm{p}}\left(\mathrm{cm}^{-1}\right)_{\text {water }}$ & E eff $(\mathrm{Mev})_{\text {water }}$ & $\left(\underline{\mathrm{S} / \rho)_{\text {water }}}\right.$ & $\left(\underline{\mathrm{S} / \rho)_{\text {air }}}\right.$ & $\left(\underline{\left.\mathrm{S} / \rho)_{\text {air }} / \mathrm{S} / \rho\right)_{\text {water }}}\right.$ \\
\hline $2 \times 2$ & 0.045 & 2.51 & 1.860 & 1.747 & 0.940 \\
$6 \times 6$ & 0.041 & 2.68 & 1.870 & 1.765 & 0.944 \\
$10 \times 10$ & 0.038 & 3.20 & 1.900 & 1.790 & 0.942 \\
$20 \times 20$ & 0.033 & 3.90 & 1.925 & 1.840 & 0.956 \\
$40 \times 40$ & 0.029 & 5.50 & 1.951 & 1.939 & 0.994 \\
\hline \hline
\end{tabular}




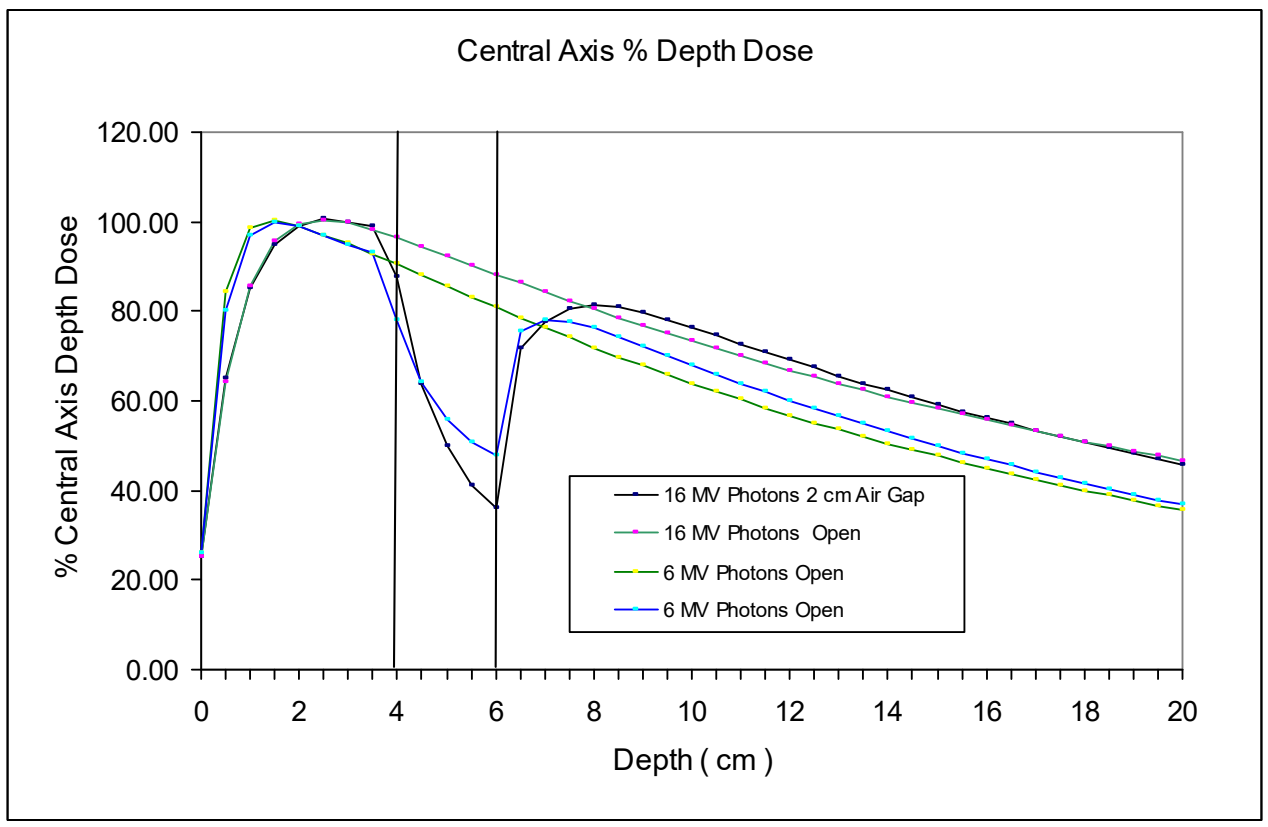

Figure 6: Central axis \%DD for a $6 \times 6 \mathrm{~cm}^{2} 6$ and $16 \mathrm{MV}$ photons with and without a $2 \mathrm{~cm}$ air gap

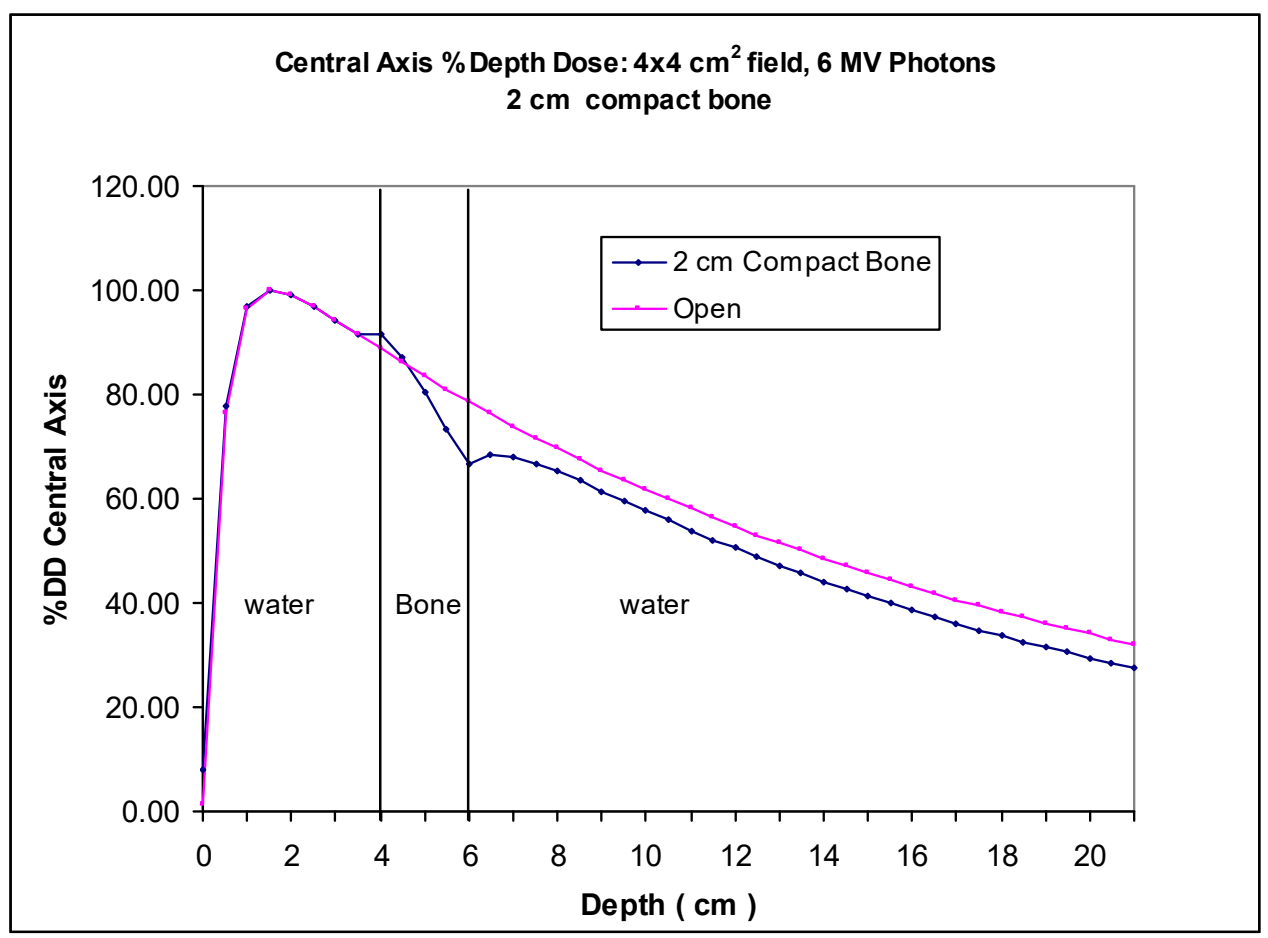

Figure 7: Loss of equilibrium on the central axis due to a high density region for a $6 \mathrm{MV}$ photons and $4 \mathrm{x} 4 \mathrm{~cm}{ }^{2}$ field size Using Varian's GEANT4 Monte Carlo environment for a simulating a 6 MV photon beam from a TrueBeam virtual linac, we calculated the central axis percentage depth dose in water with a $2 \mathrm{~cm}$ air gap. The data was compared with our model analytic calculation and excellent agreement was found. The indication that our model to a first approximation can calculate the central axis reasonably well. 


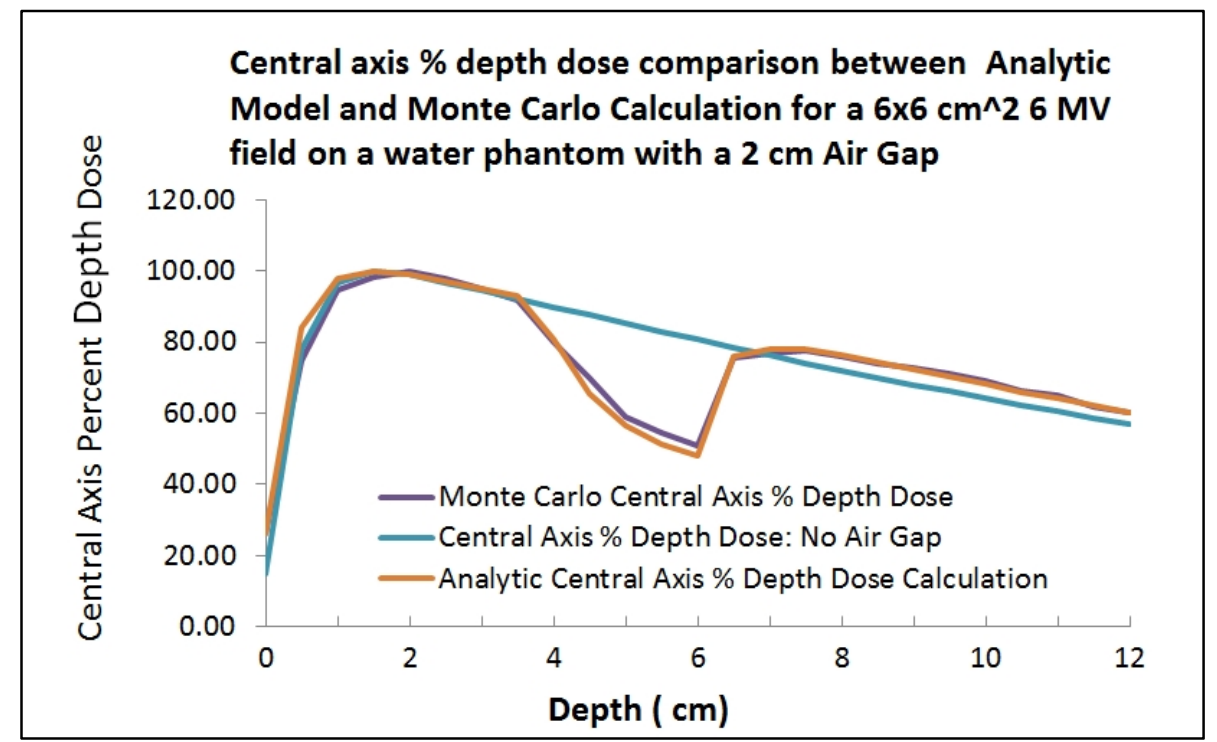

Figure 8: Comparison of calculated and Monte Carlo \%DD in a region with a $2 \mathrm{~cm}$ air gap
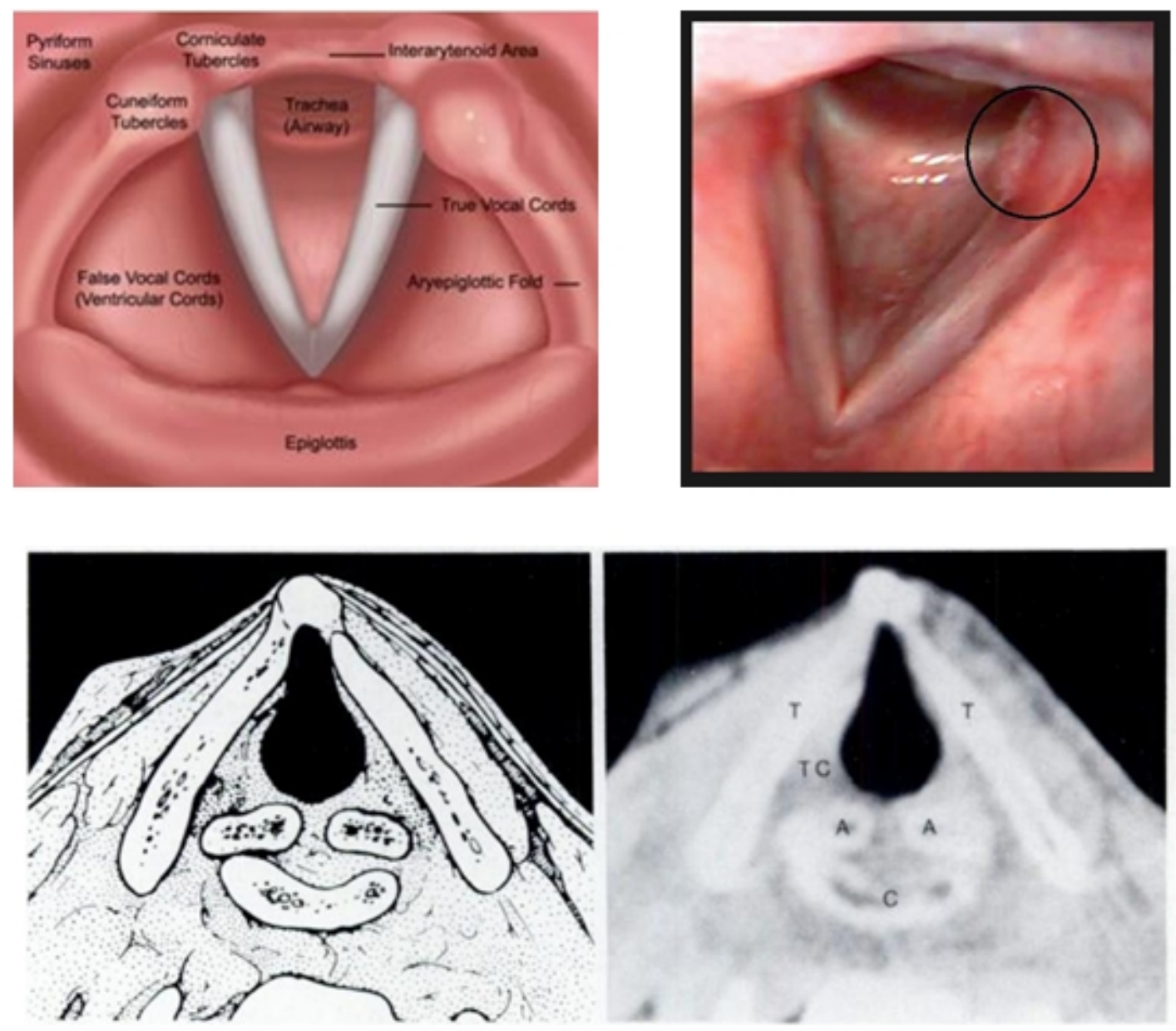

Figure 9: Geometry of a $\mathrm{T} 1$ lesion of the larynx ( $\mathrm{TC}=$ true cords; $\mathrm{T}=$ thyroid cartilage $\mathrm{A}=$ arytenoid cartilage. $\mathrm{C}=$ cricoid cartilage) 


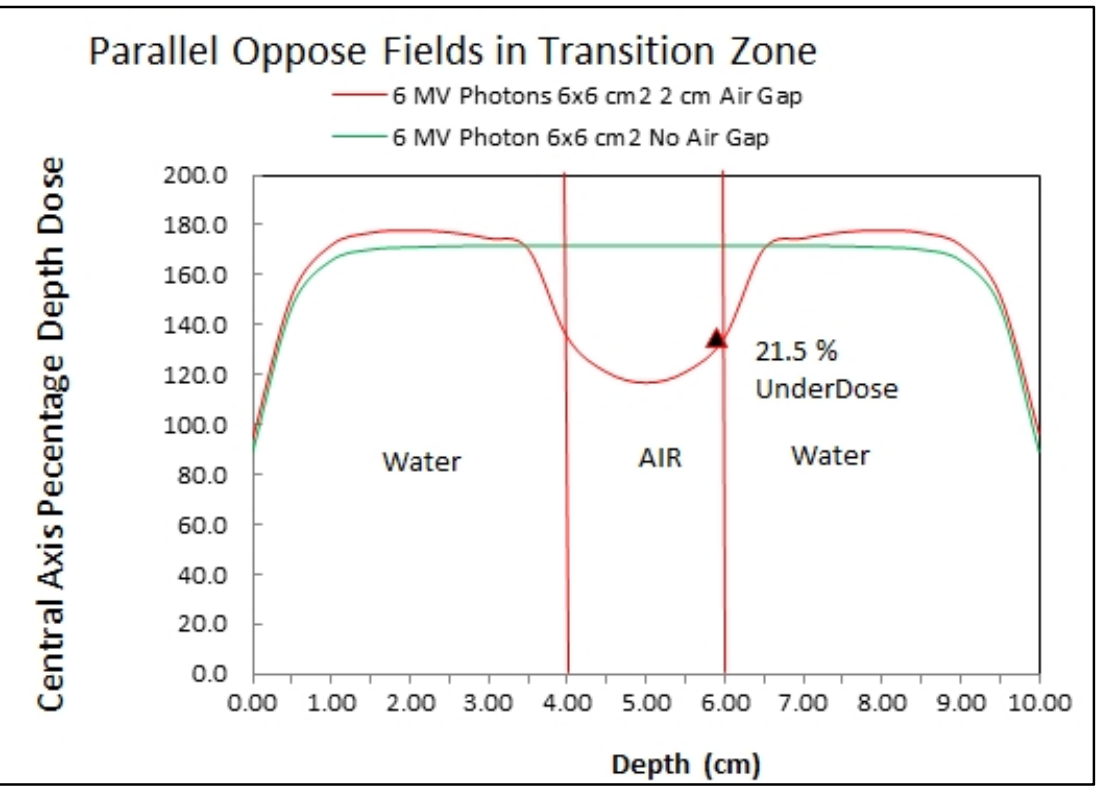

Figure 10: Central axis \%DD difference for two oppose beams $6 \times 6 \mathrm{~cm}^{2}$ with and without a $2 \mathrm{~cm}$ air gap.

\section{Results and Discussion}

\subsection{Clinical Application}

As a single modality, radiation therapy provides excellent local regional control and survival for early $\mathrm{T} 1$ vocal cord lesions. ${ }^{12,13}$ There are several ways of treating a T1 larynx lesion with radiation but for simplicity we examine a simple case where the treatment plan consist of two opposing lateral fields using $6 \mathrm{MV}$ photons. Figure 9 describes a typical geometry of a T1 larynx lesion.

For our calculation model, we assume a neck separation of $10 \mathrm{~cm}$ with an air gap of $2.0 \mathrm{~cm}$. The lesion has a diameter of $0.5 \mathrm{~cm}$. Patient setup is very crucial here and any deviation from the center of the tumor target can cause a further dose reduction. From radiobiology data and cell kinetic studies, we know that a $0.5 \mathrm{~cm}$ tumor mass has approximately $10^{7}$ viable cells and a dose of 45-50 Gy is sufficient to kill more than $95 \%$ of the cells but in clinical practice we find that doses greater than 60 Gy are needed to control a T1 lesions of the larynx. Using our model we show that the dose reduction can be up to $20 \%$ when treated with parallel oppose fields. See Figure 10.

We feel that the high dose needed to control early lesions of the larynx can only be explained by the dose inhomogeneity occurring in the transition zone between air and tissue. This has been studied by several authors. ${ }^{14,15,16,17,18}$ We recommend these simple guidelines to improve the control of early T1 lesions of the larynx: a) use field sizes $>6 \times 6 \mathrm{~cm}^{2}$ with $6 \mathrm{MV}$ only; and b) use daily Cone Beam for daily beam set up. The smaller the field size, the greater the under dosage. Higher photon energies > $6 \mathrm{MV}$ exhibit higher under dosage as well.

\section{Conclusion}

Our analytic model accurately calculates the central axis percentage depth dose of high-energy photons in both homogeneous and non-homogeneous cases. Although our model is simplistic in that an average energy is used to represent the scattering of electrons and photons. The energy loss by the photons scattering into electrons is converted into ionization energy. These ionization electrons represent our electron fluence created by the primary photons and are related to the dose in the medium. The assumptions and meaning of the coefficients in regions 1-3 have been stated precisely. By applying boundary conditions for situation with inhomogeneities, we have derived an explicit expression for the central axis percent depth dose. In the case of treating cancer of the larynx, there can be a significant reduction of dose at the tumor site. We compared our calculations with data from Monte Carlo calculations and found good agreement.

\section{Conflict of interest}

The authors declare that they have no conflicts of interest. The authors alone are responsible for the content and writing of the paper.

\section{References}

1. Pacyniak JM, Pagnamenta A. Central axis depth dose for high-energy electrons. Rad Research. 1974;60:342-46.

2. Pagnamenta A, Pacyniak JM. Calculation of central axis percentage depth dose. Particles and Fields Physics. 1980: Argonne National Laboratory (ANL). 
3. Birgani T, Karbalaee SM. Calculation of analytical expressions for measured percentage depth dose data in megavoltage photon therapy. Iranian Red Crescent Medical Journal. 2009.11(2):140-44.

4. Mayles P, Nahum A, Rosenwald JC. Handbook of Radiotherapy physics. Taylor and Francis Group;2007.

5. Johns HE. Depth dose data and isodose distributions for radiation from a $22 \mathrm{mev}$ betatron. Am J Roentgenol. 1949;62:257-68.

6. Sterling Td, Perry H, Katz L. Automation of radiation treatment planning. IV. Derivation of a Mathematical Expression for the Percent Depth Dose Surface of Cobalt -60 Beams and Visualisation of Multiple Field Dose Distributions. Br J Radiol. 1964;37:544-50.

7. Fogliata A, Vanetti E, Albers D, et al. On the dosimetric behavior of photon dose calculation algorithms in the presence of simple geometric heterogeneities: comparison with Monte Carlo calculations. Phys Med Biol. 2007;52:1363-85.

8. Salata C, Sibata CH, Ferreira NM, et al. Computer simulation of a $6 \mathrm{MV}$ photon beam in different heterogeneous media utilizing the PENELOPE code. Radiol Bras. 2009;42(4): 249-53.

9. CarrascoP, Jornet N, Duch MA, et al. Comparison of dose calculation algorithms in phantoms with lung equivalent heterogeneities under conditions of lateral electronic disequilibrium. Med Phys. 2004;31: 2899-911.

10. Haraldsson P, Knoos T, Nystrom H, et al. Monte Carlo study of TLD measurments in air cavities. Phys Med Biol. 2003;48:N253-9.

11. Miften M, Wiesmeyer M, Kapur A, et al. Comparison of RTP dose distributions in heterogeneous phantoms with the BEAM Monte Carlo simulation system. J Appl Clin Med Phys.2001;2:21-31.

12. Joshi CP, Darko J, Vidyasagar PB, et al. Dosimetry of interface region near closed air cavities for Co-60, 6 MV and 15 MV photon beams using Monte Carlo simulations. J Med Phys. 2010;35(2):73-80.

13. Harwood AR, Tierie A. Radiotherapy of early glottis cancer- -II. Int J Radiat Oncol Bio Phys. 1979;5(4):477-82.

14. Teshima $\mathrm{T}$, Chatani $\mathrm{M}$, Inoue $\mathrm{T}$. Radiation therapy for early glottic cancer (T1N0M0): II. Prospective randomized study concerning radiation field. Int J Radiat Oncol Biol Phys. 1990;18(1):119-23.

15. Epp ER, Boyer AL, Doppke KP. Underdosing of lesions resulting from lack of electronic equilibrium in upper respiratory air cavities irradiated by $10 \mathrm{MV}$ x-ray beams. Int J Radiat Oncol Bio.1977;2:613-19.

16. Behens CF. Dose build up behind air cavities for Co-60, 4, 6 and 8 MV: Measurements and Monte Carlo simulations. Phys Med Biol. 2006; 51:5937-50.

17. Epp ER, Lougheed MN, McKay JW. Ionization build-up in upper respiratory air passages during teletherapy with cobalt -60 radiation. $\mathrm{Br}$ J Radiol. 1958;31:361-7.

18. Li XA, Yu C, Holmes T. A systematic evaluation of air cavity dose perturbation in megavoltage x-ray beams. Med Phys. 2000;27:1011-7.

19. Klein EE, Chin LM, Rice RK, et al. The influence of air cavities on interface doses for photon beams. Int J Radiat Oncol Biol Phys. 1993;28:419-27. 


\section{Appendix A}

In our model we relate the electron fluence created by the interaction of primary photons scattering within the medium. The number of electrons $\mathrm{I}_{\mathrm{e}}(\mathrm{x})$, present at any depth $\mathrm{x}$, can be found by the following consideration. The number of electrons will be increased by the presence of the photons and decreased by absorption. The rate of change of the number of electrons with depth $\mathrm{x}$ is built up of two terms:

$\mathrm{dI}_{\mathrm{e}}(\mathrm{x}) / \mathrm{dx}=-\mu_{\mathrm{e}} \mathrm{Ie}_{\mathrm{e}}(\mathrm{x})+\alpha \operatorname{Ip}(\mathrm{x})$

Here, $\mu_{\mathrm{e}}\left(\mathrm{cm}^{-1}\right)$ an effective linear absorption coefficient for the electrons in the given medium 1 . To simplify the derivation, to a first approximation, $\mu_{\mathrm{e}}$ is independent of energy or better has an average value. The number $\alpha$ is the ionization coefficient. It tells us how efficiently free electrons are created by the photons and it includes primary electrons slowing down through soft collisions as well as hard, knock-on collisions. The right most term in (1) is properly referred to as the driving term as it is the photons intensity, $\mathrm{I}_{\mathrm{p}}(\mathrm{x})$, which generates the electrons.

Substitution of (6) into (1) leads to a simple linear differential equation

$\mathrm{dI}_{\mathrm{e}}(\mathrm{x}) / \mathrm{dx}=-\mu_{\mathrm{e}} \mathrm{I}_{\mathrm{e}}(\mathrm{x})+\alpha \mathrm{I}_{\mathrm{o}} \exp \left(-\mu_{\mathrm{p}} \mathrm{x}\right)$

This has the most general solution

$\mathrm{I}_{\mathrm{e}}(\mathrm{x})=\mathrm{C}_{1} \exp \left(-\mu_{\mathrm{e}} \mathrm{x}\right)+\mathrm{C}_{2} \exp \left(-\mu_{\mathrm{p}} \mathrm{x}\right)$

this is easily verified by substitution with

$\mathrm{C}_{2}=\alpha \mathrm{I}_{\mathrm{o}} /\left(\mu_{\mathrm{e}}-\mu_{\mathrm{p}}\right)$

The coefficient $\mathrm{C} 1$ is determined by the boundary condition, namely that the dose at the surface or skin dose is $\mathrm{Ie}(0)$, we find from (14) at $\mathrm{x}=0$

$\mathrm{I}_{\mathrm{e}}(0)=\mathrm{C}_{1}+\alpha \mathrm{I}_{\mathrm{o}} /\left(\mu_{\mathrm{e}}-\mu_{\mathrm{p}}\right)$

and

$\mathrm{C}_{1}=\mathrm{I}_{\mathrm{e}}(0)-\alpha \mathrm{I}_{\mathrm{o}} /\left(\mu_{\mathrm{e}}-\mu_{\mathrm{p}}\right)$

Substitution of the coefficient $\mathrm{C}_{1}$ and $\mathrm{C}_{2}$ into (3) gives a general formula for the electron flux

first term second term last term

$\mathrm{I}_{\mathrm{e}}(\mathrm{x})=\mathrm{I}_{\mathrm{e}}(0) \exp \left(-\mu_{\mathrm{e}} \mathrm{X}\right)+\left(\alpha \mathrm{I}_{\mathrm{o}} /\left(\mu_{\mathrm{e} 1}-\mu_{\mathrm{p}}\right)\right)\left[\exp \left(-\mu_{\mathrm{p}} \mathrm{x}\right)-\exp \left(-\mu_{\mathrm{e}} \mathrm{x}\right)\right]$

The first term represent the number of electrons at the surface of the medium. These electrons may come from the ionization of air molecules scattering from the inner collimators of the linear accelerator, etc. As the exponential associated with this term tells us, they are quickly absorbed and do not penetrate very deeply. This accounts for the low surface dose encountered with megavoltage photon beams. $\mathrm{I}_{\mathrm{e}}(0)$ depends on the incoming photons and thus is a function of the field size.

The second term simply represents the ionized electrons produced by the primary photons. This term falls off very slowly as the mean free path of high energy photons in low $\mathrm{Z}$ materials is high. Experimentally we find that $\mu_{\mathrm{e}}>>$ $\mu_{\mathrm{p}}$ and for large value of $\mathrm{x}$, we have

$\mathrm{I}_{\mathrm{e}}(\mathrm{x}) \sim\left[\alpha \mathrm{I}_{\mathrm{o}} /\left(\mu_{\mathrm{e}}-\mu_{\mathrm{p}}\right)\right] \exp \left(-\mu_{\mathrm{p}} \mathrm{x}\right)$ for $\mathrm{x}>>1$

The last term has a minus sign in front. It subtracts from the second term the ionization electrons which are absorbed and therefore no longer contribute to the total ionization.

Eq. (18) shows a maximum at some depth $\mathrm{x}=\mathrm{xm}$ when we set

$\mathrm{dI}_{\mathrm{e}}(\mathrm{x}) / \mathrm{dx}=0 \quad$ at $\mathrm{x}=\mathrm{x}_{\mathrm{m}}$ 
This allows us to solve for $\mathrm{I}_{\mathrm{e}}(0)$ using equs. (13) and (14).

$\mathrm{Ie}_{\mathrm{e}}(0)=\left(\alpha \mathrm{I}_{\mathrm{o}} /\left(\mu_{\mathrm{e}}-\mu_{\mathrm{p}}\right)\right)\left\{\left(1-\left(\mu_{\mathrm{p}} / \mu_{\mathrm{e}}\right)\right) \exp -\left(\mu_{\mathrm{e}}-\mu_{\mathrm{p}}\right) \mathrm{x}_{\mathrm{m}}\right\}$

this shows that Ie(0) also depends on $\quad \alpha$ and proves the claim that it too is due to ionizing photons.

Substituting (10) into (7) we obtain

$\mathrm{Ie}(\mathrm{x})=\left(\alpha \mathrm{I}_{\mathrm{o}} /\left(\mu_{\mathrm{e}}-\mu_{\mathrm{p}}\right)\right)\left\{\mu_{\mathrm{e}} \exp -\mu_{\mathrm{p}}\left(\mathrm{x}-\mathrm{X}_{\mathrm{m}}\right)-\mu_{\mathrm{p}} \exp -\mu_{\mathrm{e}}\left(\mathrm{x}-\mathrm{x}_{\mathrm{m}}\right)\right\}\left[\exp -\left(\mu_{\mathrm{p}} \mathrm{X}_{\mathrm{m}}\right) / \mu_{\mathrm{e}}\right]$

at $\mathrm{x}=\mathrm{Xm}$

$\mathrm{I}_{\mathrm{e}}\left(\mathrm{x}_{\mathrm{m}}\right)=\left[\alpha \mathrm{I}_{\mathrm{o}} /\left(\mu_{\mathrm{e}}-\mu_{\mathrm{p}}\right)\right] \exp -\left(\mu_{\mathrm{p}} \mathrm{x}_{\mathrm{m}}\right)$

Using the definition of central axis \% depth dose (Eq.9), our final expression is:

$\% \mathrm{D}(\mathrm{x})=100\left[\mathrm{I} e(\mathrm{x}) / \mathrm{I}_{\mathrm{e}}\left(\mathrm{x}_{\mathrm{m}}\right)\right]\left[\left(\mathrm{f}+\mathrm{x}_{\mathrm{m}}\right) /(\mathrm{f}+\mathrm{x})\right]^{2}$

$\% \mathrm{D}(\mathrm{x})=100\left[1 /\left(\mu_{\mathrm{e}}-\mu_{\mathrm{p}}\right)\right]\left[\left(\mathrm{f}+\mathrm{x}_{\mathrm{m}}\right) /(\mathrm{f}+\mathrm{x})\right]^{2}\left\{\mu_{\mathrm{e}} \exp -\mu_{\mathrm{p}}\left(\mathrm{x}-\mathrm{x}_{\mathrm{m}}\right)-\mu_{\mathrm{p}} \exp -\mu_{\mathrm{e}}\left(\mathrm{x}-\mathrm{x}_{\mathrm{m}}\right)\right\}$

At $x=0$

$$
\left.\% D(0)=100\left[1 /\left(\mu_{e}-\mu_{p}\right)\right]\left[\left(f+X_{m}\right) / f\right)^{2}\right]\left[\mu_{e} \exp \left(\mu_{p} X_{m}\right)-\mu_{p} \exp \left(\mu_{e} X_{m}\right)\right]
$$

The surface dose is small but not zero. It is interesting to note that Eq. (15) agrees closely with the form obtained empirically by Johns et al. ${ }^{5}$ many years ago and others (Tahmasei et al.) ${ }^{3,6}$. The difference lies in the fact that we have derived(Eq. 25) from a model which has allowed us to state precisely the assumptions given, the necessary approximations and the meaning of the different coefficients. Eq. (25) calculates the central axis percentage depth dose for high energy photons as a function of the average photon energy, $\mu_{p}$, an average secondary electron factor, $\mu_{e}$, source to skin distance $\mathrm{f}$ and depth of maximum dose $\mathrm{xm}$. Figure 2 shows the calculated vs measured $\%$ depth dose for field sizes $2 \times 2$ to $40 \times 40 \mathrm{~cm}^{2}$ with an accuracy of $\pm 2 \%$ over a range of 0 to $30 \mathrm{~cm} \mathrm{depth}$. 


\section{Appendix B}

Derivation of \%depth dose with in homogeneities

Region1: $\mathrm{x} \geq 0$ (Homogeneous Case)

$\% D(x)=100\left[1 /\left(\mu_{e}-\mu_{p}\right)\right]\left[\left(f+x_{m}\right) /(f+x)\right]^{2}\left\{\mu_{e} \exp -\mu_{p}\left(x-x_{m}\right)-\mu_{p} \exp -\mu_{e}\left(x-x_{m}\right)\right\}$

Region 2: $\mathrm{a} \leq \mathrm{x} \leq \mathrm{b}$ (low density - Air: $\mu_{\mathrm{p} 2} \ll \mu_{\mathrm{p} 1}$ )

Let $\mu_{\mathrm{p} 2}$ be an effective linear attenuation coefficient for the photons in medium 2 with density, $\rho_{2}$

Following our earlier derivation for the percentage depth dose, Eqs. (11-15),

let $x^{\prime}=(x-a)$ and

$\mathrm{dI}_{\mathrm{e} 2}\left(\mathrm{x}^{\prime}\right) / \mathrm{dx} \mathrm{x}^{\prime}=-\mu_{\mathrm{e} 2} \mathrm{Ie}_{\mathrm{e} 2}\left(\mathrm{x}^{\prime}\right)+\alpha_{2} \mathrm{I}_{0} \exp \left(-\mu_{\mathrm{p} 2}\left(\mathrm{x}^{\prime}\right)\right)$

This has the most general solution

$$
\begin{aligned}
& \mathrm{I}_{\mathrm{e} 2}\left(\mathrm{x}^{\prime}\right)=\mathrm{C}_{1} \exp \left(-\mu_{\mathrm{e} 2} \mathrm{X}^{\prime}\right)+\mathrm{C}_{2} \exp \left(-\mu_{\mathrm{p} 2} \mathrm{x}^{\prime}\right) \\
& \text { where } \mathrm{C}_{2}=\alpha_{2} \mathrm{I}_{0} \exp \left(-\mu_{\mathrm{p} 1 \mathrm{a}}\right) \quad /\left(\mu_{\mathrm{e} 2}-\mu_{\mathrm{p} 2}\right)
\end{aligned}
$$

Solving for $\mathrm{I}_{\mathrm{e} 2}\left(\mathrm{x}^{\prime}\right)$, we get

$\left.\mathrm{I}_{\mathrm{e} 2}\left(\mathrm{x}^{\prime}\right)=\mathrm{C}_{1} \exp -\left(\mu_{\mathrm{e} 2} \mathrm{x}^{\prime}\right)+\alpha_{2} \mathrm{I}_{0} \exp \left(-\mu_{\mathrm{p} 1} \mathrm{a}\right) \exp \left(-\mu_{\mathrm{p} 2} \mathrm{x}^{\prime}\right) /\left(\mu_{\mathrm{e} 2}-\mu_{\mathrm{p} 2}\right)\right)$

at $\mathrm{x}=\mathrm{a} \quad \mathrm{x}^{\prime}=0$

$\mathrm{I}_{\mathrm{e} 2}(0)=\mathrm{C}_{1}+\alpha_{2} \mathrm{I}_{0} \exp \left(-\mu_{\mathrm{p} 1 \mathrm{a}} \mathrm{a}\right) /\left(\mu_{\mathrm{e} 2}-\mu_{\mathrm{p} 2}\right)$

and $\mathrm{C}_{1}=\mathrm{I}_{\mathrm{e} 2}(0)-\alpha_{2} \mathrm{I}_{0} \exp \left(-\mu_{\mathrm{p} 1} \mathrm{a}\right) /\left(\mu_{\mathrm{e} 2}-\mu_{\mathrm{p} 2}\right)$

Substituting (6) into (3), we have

$\mathrm{I}_{\mathrm{e} 2}\left(\mathrm{x}^{\prime}\right)=\left(\mathrm{I}_{\mathrm{e} 2}(0)-\left(\alpha_{2} \mathrm{I}_{0} \exp \left(-\mu_{\mathrm{p} 1} \mathrm{a}\right) /\left(\mu_{\mathrm{e} 2}-\mu_{\mathrm{p} 2}\right)\right)\right) \exp \left(-\mu_{\mathrm{e} 2} \mathrm{x}^{\prime}\right)$

$+\left(\alpha_{2} I_{0} \exp \left(-\mu_{\mathrm{p} 1} \mathrm{a}\right) /\left(\mu_{\mathrm{e} 2}-\mu_{\mathrm{p} 2}\right)\right) \exp \left(-\mu_{\mathrm{p} 2} \mathrm{x}^{\prime}\right)$

From our $\mathrm{BC}$ at $\mathrm{x}=\mathrm{a}, \mathrm{x}^{\prime}=0$

$\mathrm{I}_{\mathrm{e} 1}(\mathrm{a})=\mathrm{I}_{\mathrm{e} 2}(0)=\left(\alpha_{1} \mathrm{I}_{\mathrm{o}} \exp \left(-\mu_{\mathrm{p} 1} \mathrm{a}\right) /\left(\mu_{\mathrm{e} 1}-\mu_{\mathrm{p} 1}\right)\right)\left(\exp \left(-\mu_{\mathrm{p}} \mathrm{X}_{\mathrm{m} 1}\right) / \mu_{\mathrm{e} 1}\right)$

$x\left(\mu_{\mathrm{e} 1} \exp -\left(\mu_{\mathrm{p} 1}\left(\mathrm{a}-\mathrm{x}_{\mathrm{m} 1}\right)\right)-\mu_{\mathrm{p} 1} \exp -\left(\mu_{\mathrm{e} 1}\left(\mathrm{a}-\mathrm{x}_{\mathrm{m} 1}\right)\right)\right)$

Substituting (8) into (7),

$\mathrm{I}_{\mathrm{e} 2}\left(\mathrm{x}^{\prime}\right)=\exp \left(-\mu_{\mathrm{e} 2} \mathrm{X}^{\prime}\right)\left\{\left(\alpha_{1} \mathrm{I}_{\mathrm{o}} \exp \left(-\mu_{\mathrm{p} 1} \mathrm{a}\right) /\left(\mu_{\mathrm{e} 1}-\mu_{\mathrm{p} 1}\right)\right)\left(\exp \left(-\mu_{\mathrm{p} 1} \mathrm{X}_{\mathrm{m} 1}\right) / \mu_{\mathrm{e} 1}\right)\right.$

$\left.x\left(\mu_{\mathrm{e} 1} \exp -\mu_{\mathrm{p} 1}\left(\mathrm{a}-\mathrm{x}_{\mathrm{m} 1}\right)-\mu_{\mathrm{p} 1} \exp -\mu_{\mathrm{e} 1}\left(\mathrm{a}-\mathrm{x}_{\mathrm{m} 1}\right)\right)-\left(\alpha_{2} \mathrm{I}_{0} \exp \left(-\mu_{\mathrm{p} 1 \mathrm{a}}\right) /\left(\mu_{\mathrm{e} 2}-\mu_{\mathrm{p} 2}\right)\right)\right\}$

$+\left(\alpha_{2} \mathrm{I}_{0} \exp \left(-\mu_{\mathrm{p} 1 \mathrm{a}}\right) /\left(\mu_{\mathrm{e} 2}-\mu_{\mathrm{p} 2}\right)\right) \exp \left(-\mu_{\mathrm{p} 2} \mathrm{x}^{\prime}\right)$ 
From our definition of percentage depth dose equ. (7), we have

$$
\begin{aligned}
\% \mathrm{D}_{2}\left(\mathrm{x}^{\prime}\right)= & 100\left[\mathrm{D}_{2}\left(\mathrm{x}^{\prime}\right) / \mathrm{D}_{1}\left(\mathrm{x}_{\mathrm{max}}\right)\right] \\
& \text { where, } \mathrm{D}_{1}\left(\mathrm{x}_{\max }\right)=\mathrm{S}_{1}\left(\mathrm{f} /\left(\mathrm{f}+\mathrm{x}_{\mathrm{m} 1}\right)^{2}\left(\alpha_{1} \mathrm{I}_{\mathrm{o}} \exp \left(-\mu_{\mathrm{p} 1} \mathrm{x}_{\mathrm{m} 1}\right) / \mu_{\mathrm{e} 1)}\right.\right. \\
& \text { and } \mathrm{D} 2\left(\mathrm{x}^{\prime}\right)=100\left(\mathrm{~S}_{2} / \mathrm{S}_{1}\right)\left[(\mathrm{f}+\mathrm{a}) /(\mathrm{f}+\mathrm{x})^{2} /\left(\left(\mathrm{f}+\mathrm{x}_{\mathrm{m} 1}\right) / \mathrm{f}\right)^{2} \quad\left\{\mathrm{I}_{\mathrm{e} 2}\left(\mathrm{x}^{\prime}\right) / \mathrm{I}_{\mathrm{e} 1}\left(\mathrm{x}_{\mathrm{m} 1}\right)\right\}\right.
\end{aligned}
$$

Dividing (12 by (11)

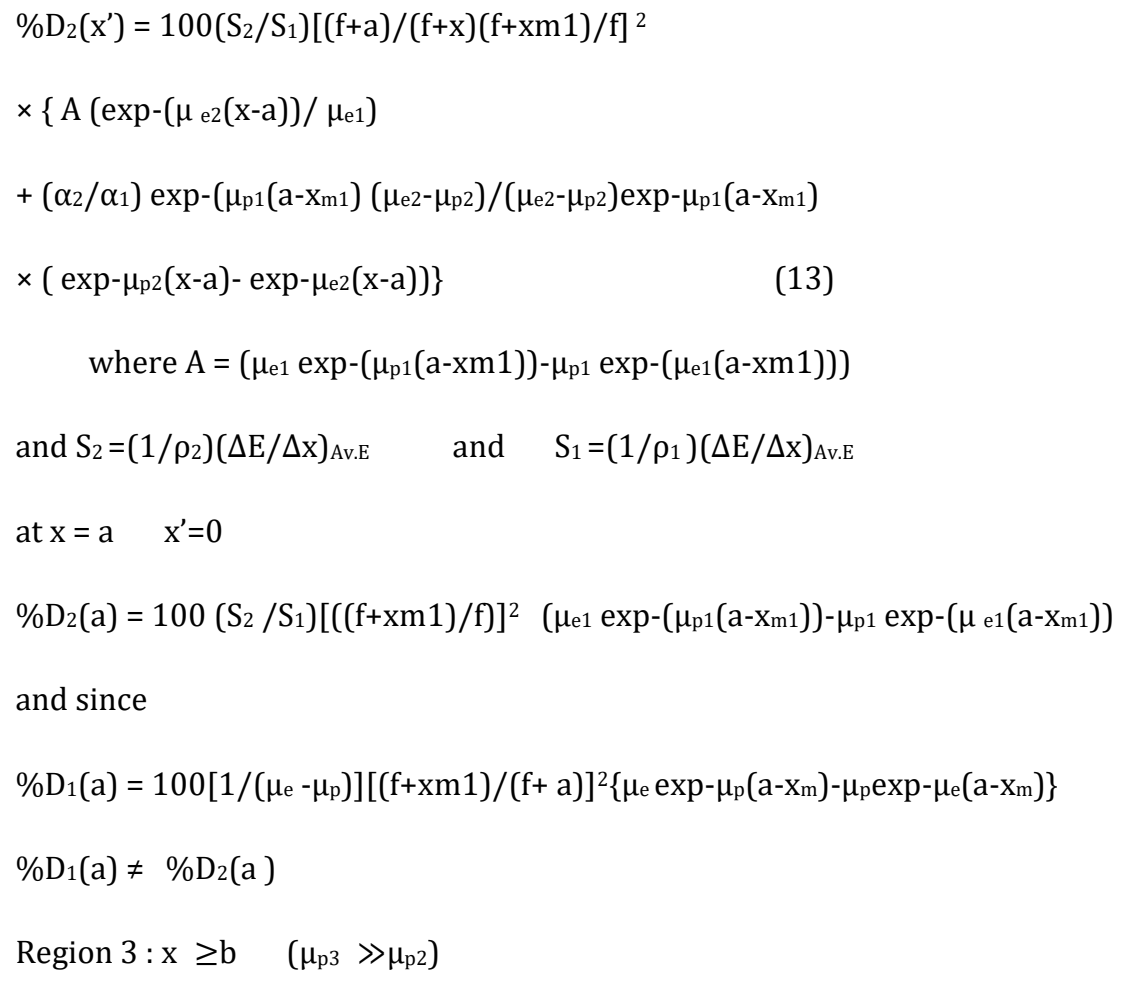

and $\operatorname{Ip} 3\left(x^{\prime}\right)=I_{0} e^{-\mu_{p} 1^{a}} e^{-\mu_{p 2}{ }^{b}} e^{-\mu_{p} 3^{\prime}}$

This has the most general solution

$\mathrm{I}_{\mathrm{e} 3}\left(\mathrm{x}^{\prime}\right)=\mathrm{C}_{1} \exp \left(-\mu_{\mathrm{e} 3} \mathrm{x}^{\prime}\right)+\mathrm{C}_{2} \exp \left(-\mu_{\mathrm{p} 3} \mathrm{x}^{\prime}\right)$ 
$\mathrm{I}_{\mathrm{e} 3}\left(\mathrm{x}^{\prime}\right)=\mathrm{C}_{1} \exp \left(-\mu_{\mathrm{e} 3 \mathrm{x}^{\prime}}\right)+\left[\left(\alpha_{2} \mathrm{I}_{0} \exp \left(-\mu_{\mathrm{p} 1} \mathrm{a}\right)\right) /\left(\mu_{\mathrm{e} 2}-\mu_{\mathrm{p} 2}\right)\right] \exp \left(-\mu_{\mathrm{p} 3} \mathrm{x}^{\prime}\right)$

where $C_{2}=\left(\alpha_{2} I_{0} \exp \left(-\mu_{\mathrm{p} 1} \mathrm{a}\right)\right) /\left(\mu_{\mathrm{e} 2}-\mu_{\mathrm{p} 2}\right)$ and can be easily verified by substitution

at $\mathrm{x}=\mathrm{b}$

$\mathrm{I}_{\mathrm{e}}(\mathrm{b})=\mathrm{C}_{1}+\left(\alpha_{3} \mathrm{I}_{0} \exp \left(-\mu_{\mathrm{p} 1} \mathrm{~b}\right)\right) /\left(\mu_{\mathrm{e} 3}-\mu_{\mathrm{p} 3}\right)$

and $\mathrm{C} 1=\left[\mathrm{I}_{\mathrm{e} 3}(\mathrm{~b})-\left(\alpha_{3} \mathrm{I}_{0} \mathrm{e}^{-\mu_{\mathrm{p} 2}{ }^{\mathrm{a}}}\right) /\left(\mu_{\mathrm{e} 3}-\mu_{\mathrm{p} 3}\right)\right]$

Rewriting, (19) we have

$\mathrm{I}_{\mathrm{e} 3}\left(\mathrm{x}^{\prime}\right)=\left[\mathrm{I}_{\mathrm{e} 3}(\mathrm{~b})-\left(\alpha_{3} \mathrm{I}_{0} \mathrm{e}^{-\mu_{\mathrm{p} 2} 2^{\mathrm{a}}}\right) /\left(\mu_{\mathrm{e} 3}-\mu_{\mathrm{p} 3}\right)\right] \mathrm{e}^{-\mu_{\mathrm{e} 2} \mathrm{x}^{\prime}}+\left(\alpha_{3} \mathrm{I}_{0} \mathrm{e}^{-\mu_{\mathrm{p} 2} \mathrm{~b}} \mathrm{e}^{-\mu_{\mathrm{p}} 3^{\prime}}\right) /\left(\mu_{\mathrm{e} 3}-\mu_{\mathrm{p} 3}\right)$

Equ. (17) shows a maximum at a depth $\mathrm{x}=\mathrm{x}_{\mathrm{m} 3}$ where

$\mathrm{d}\left(\mathrm{I}_{\mathrm{e} 3}\right) / \mathrm{d} \mathrm{x}^{\prime}=0 \quad$ at $\mathrm{x}^{\prime}=\mathrm{x}_{\mathrm{m} 3}$

This follows from our earlier discussion of the central axis for the homogeneous case.

We find that at $\mathrm{x}^{\prime}=\mathrm{b}$

$\left.\mathrm{I}_{\mathrm{e} 3}(\mathrm{~b})=\left[\alpha_{3} \mathrm{I}_{2}(\mathrm{~b}) /\left(\mu_{\mathrm{e} 3}-\mu_{\mathrm{p} 3}\right)\right]\right)\left\{\left(1-\left(\mu_{\mathrm{p} 3} / \mu_{\mathrm{e} 3}\right)\right) \exp -\left(\mu_{\mathrm{p} 3}-\mu_{\mathrm{e} 3}\right)\left(\mathrm{x}_{\mathrm{m} 3}-\mathrm{b}\right)\right\}$

Substituting (24) into (22) and some algebra the electron flux distribution in region 3 is

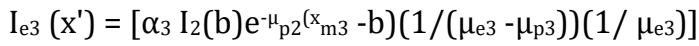

$\mathrm{x}\left\{\mu_{\mathrm{e} 3} \exp -\mu_{\mathrm{p} 3}\left(\mathrm{x}-\mathrm{x}_{\mathrm{m} 3}\right)-\mu_{\mathrm{p} 3} \exp -\mu_{\mathrm{e} 3}\left(\mathrm{x}-\mathrm{x}_{\mathrm{m} 3}\right)\right\}$

Eq. (25) is similar in form to Eq. (12) for the homogeneous case.

Working with an average energy for the stopping power and a constant value the dose in region 3 is given by

$\mathrm{D}_{3}\left(\mathrm{x}^{\prime}\right)=\mathrm{I}_{\mathrm{e} 3}\left(\mathrm{x}^{\prime}\right) \mathrm{S}_{3}\left((\mathrm{f}+\mathrm{b}) /\left(\mathrm{f}+\mathrm{b}+\mathrm{x}^{\prime}\right)\right)^{2}$

$D_{1}\left(x_{m 1}\right)=\left(\alpha_{1} I_{0} /\left(\mu_{e 1}-\mu_{p 1}\right) e^{-\mu_{p 1} x_{m 1}}\right) S_{1}\left(f /\left(f+x_{m 1}\right)\right)$

where $\left.S_{3}=\left(1 / \rho_{3}\right)(\Delta \mathrm{E} / \Delta \mathrm{x})\right)_{\mathrm{Av} . \mathrm{E}}$

and $\quad S_{1}=\left(1 / \rho_{1}(\Delta E / \Delta x)\right)_{A v . E}$

and the percent depth dose is

$\% \mathrm{D}_{3}\left(\mathrm{x}^{\prime}\right)=100\left(\left(\mathrm{D}_{3}\left(\mathrm{x}^{\prime}\right) / \mathrm{D}_{1}\left(\mathrm{x}_{\mathrm{m} 1}\right)\right)\right.$

Simplifying, we find

$\left.\% \mathrm{D}_{3}(\mathrm{x}-\mathrm{b})=100\left(\mathrm{~S}_{3} / \mathrm{S}_{1}\right)\left(\alpha_{3} / \alpha_{1}\right)\left(\mu_{\mathrm{e} 3} / \mu_{\mathrm{e} 1}\right)\left[1 /\left(\mu_{\mathrm{e} 3}-\mu_{\mathrm{p} 3}\right)\right](\mathrm{f}+\mathrm{b}) /(\mathrm{f}+\mathrm{b}+\mathrm{x})\left(\mathrm{f}+\mathrm{x}_{\mathrm{m} 1}\right) / \mathrm{f}\right)^{2}$

$\times\left(\exp -\left(\mu_{\mathrm{p} 1} \mathrm{a}\right) \exp -\left(\mu_{\mathrm{p} 2}(\mathrm{~b}-\mathrm{a})\right) \exp -\left(\mu_{\mathrm{p} 3} \mathrm{X}_{\mathrm{m} 3}\right)\right)$ 
$\times\left\{\mu_{\mathrm{e} 3} \exp -\mu_{\mathrm{p} 3}\left(\mathrm{x}^{\prime}-\mathrm{x}_{\mathrm{m} 3}\right)-\mu_{\mathrm{p} 3} \exp -\mu_{\mathrm{e} 3}\left(\mathrm{x}^{\prime}-\mathrm{x}_{\mathrm{m} 3}\right)\right\}$

at $\quad \mathrm{x}=\mathrm{b} ; \quad \mathrm{x}^{\prime}=0$

$\% \mathrm{D}_{3}(0)=100\left(\mathrm{~S}_{3} / \mathrm{S}_{1}\right)\left(\alpha_{3} / \alpha_{1}\right)\left(\mu_{\mathrm{e} 3} / \mu_{\mathrm{e} 1}\right)\left[1 /\left(\mu_{\mathrm{e} 3}-\mu_{\mathrm{p} 3}\right)\right]$

$\times\left(\exp -\left(\mu_{\mathrm{p} 1} \mathrm{a}\right) \exp -\left(\mu_{\mathrm{p} 2}(\mathrm{~b}-\mathrm{a})\right) \exp -\left(\mu_{\mathrm{p} 3 \mathrm{Xm} 3}\right)\right)$

$\times\left\{\mu_{\mathrm{e} 3} \exp -\mu_{\mathrm{p} 3}\left(\mathrm{x}^{\prime}-\mathrm{x}_{\mathrm{m} 3}\right)-\mu_{\mathrm{p} 3} \exp -\mu_{\mathrm{e} 3}\left(\mathrm{x}^{\prime}-\mathrm{x}_{\mathrm{m} 3}\right)\right\}$

which differs from

$\% \mathrm{D}_{2}(\mathrm{~b})=100\left(\mathrm{~S}_{2} / \mathrm{S}_{1}\right)\left[(\mathrm{f}+\mathrm{b})\left(\mathrm{f}+\mathrm{x}_{\mathrm{m} 1}\right) /(\mathrm{f}(\mathrm{f}+\mathrm{a}+\mathrm{b})]\right.$

$\times\left\{\left(\mu_{\mathrm{e} 1} \exp -\left(\mu_{\mathrm{p} 1}(\mathrm{a}-\mathrm{xm} 1)\right)-\mu_{\mathrm{p} 1} \exp -\left(\mu_{\mathrm{e} 1}(\mathrm{a}-\mathrm{xm} 1)\right)\right) \exp -\left(\mu_{\mathrm{e} 2}(\mathrm{~b}-\mathrm{a})\right)\right.$

$\left.\left.+\left(\alpha_{2} / \alpha_{1}\right) \exp -\left(\mu_{\mathrm{p} 1}\left(\mathrm{a}-\mathrm{X}_{\mathrm{m} 1}\right)\right)\left(\mu_{\mathrm{e} 1} / \mu_{\mathrm{e} 2}\right)\right) \exp -\mu_{\mathrm{p} 1}\left(\mathrm{a}-\mathrm{X}_{\mathrm{m} 1}\right)\left(1-\exp -\mu_{\mathrm{e} 2}(\mathrm{~b}-\mathrm{a})\right)\right\}$ 